\title{
Evaluation of toxic air pollutants in an urban neighborhood adjacent to a municipal waste landfill
}

\author{
P. Scheff ${ }^{1}$, C. Casten ${ }^{1}$, P. Ruesch ${ }^{2}$ and M. Friedl ${ }^{3}$ \\ ${ }^{1}$ Department of Environmental and Occupational Health Sciences, \\ University of Illinois at Chicago, U.S.A. \\ ${ }^{2}$ U.S. Environmental Protection Agency, Region 5, Chicago, U.S.A. \\ ${ }^{3}$ Cincinnati, Ohio, U.S.A.
}

\section{Abstract}

In response to community concerns, a comprehensive toxic air pollutant measurement study was carried out in a low-income community in the Cincinnati metropolitan area. The study was directed by a collaborative board with representatives from the City, County, State, and Federal environmental agencies, community organizations and local industries. The community studied was surrounded by many potential sources of toxic air pollution including manufacturing facilities, highways and solid-waste landfills. Emission of toxic chemicals from the nearby municipal landfill was of particular concern. Air sampling of volatile organic compounds (VOC), semi-volatile organic compounds (SVOC), particulate matter, metals, and acid gases, was performed by the County Department of Environmental Services from September 1997 to September 1998. The sampling network consiste : of four community sites and one comparison site located in another area of the City. Toxic materials found in the landfill gas and that were detected greater than 50\% of the time during community monitoring include acetone, benzene, ethylbenzene, toluene and xylene. A receptor model for landfill and vehicle emissions was developed. This model suggested that approximately $20 \%$ of the measured toluene and xylene, $40 \%$ of the ethylbenzene, and greater than $90 \%$ of perchloroethylene and methylene chloride concentrations in the community were from the landfill. Relationships between air toxic concentration and time downwind of the landfill were also studied. This study shows that a municipal-waste landfill can be a significant contributor of toxic air pollutants in a neighboring community. 


\section{Introduction}

The U.S. Environmental Protection Agency (USEPA) has identified 188 hazardous air pollutants (HAPs) in section 112(b) of the Clean Air Act as amended in 1990 [1]. The pollutants listed as HAPs include industrial chemicals, solvents, pesticides and combustion by-products. Breathing air that contains HAPs can be harmful to human health as these pollutants are associated with cancer as well as adverse neurological, reproductive and developmental effects. Many of the compounds targeted by the measurement methods used in this study are listed as HAPs.

The Winton Hills and Winton Place neighborhoods of Cincinnati are home to many large industrial facilities, landfills, and a major highway/railway corridor. In an effort to address concerns about local air quality, a collaborative group representing citizens, local industry and government devised an extensive sampling project to evaluate air quality in the neighborhoods. The objective of the monitoring project was to characterize air quality by identifying and quantifying ambient air contaminants throughout communities by sampling for volatile and semi-volatile organic compounds, metals, acid gases, ammonia, and particulate less than or equal to 10 microns $\left(\mathrm{PM}_{10}\right)$ in size with an expanded network of monitors. This paper will specifically focus on concentrations of volatile organic compounds. Complete details of the study have been published [2].

Many potential pollutant sources are located within the Winton Hills/Place communities. In addition to motor vehicles on the area's expressways, landfills within the community were specifically believed to be sources of HAPs prior to capping. Landfill gas analyses performed in the early 1990's identify compounds such as ethylbenzene, methylene chloride, perchloroethylene, toluene and xylene being emitted. Industry surrounding the communities is also a potential source of pollutants. USEPA Toxic Release Inventory (TRI) data gives a partial view of the toxic releases from area industry, but does not account for all emissions by the companies. This is because only certain industrial sectors are required to report TRI data and they are only required to report on releases of chemicals specified by the EPA. Compounds emitted by industries within Winton Hills/Place that are on the TRI list include ammonia, methanol, phthalic anhydride, sulfuric acid, hydrochloric acid, toluene, zinc, nickel, copper, manganese and chromium [3].

\section{Methods}

\subsection{Sampling and analysis}

In the sampling plan, there were five fixed sites with each site equipped to sample for at least the three main groups of compounds and elements of interest. Four sites were in the main sampling area. Those sites include Winton Montessori School, the Jacobs Center, the firehouse on Circle Avenue and a maintenance building on Winneste Avenue. One site was located as a 
comparison sampler in another Cincinnati area (Dater Junior High). All samples, when possible, were collected over a 24-hour period from noon until noon the following day.

Volatile organic compounds were collected in six-liter electropolished SUMMA® canisters. An electronic timer was used to control a pump and solenoid valve allowing air to be pumped into the canister. The flow rate was adjusted to allow approximately 14,400 cubic centimeters (cc) of air to be collected during the twenty-four hour period as specified in EPA's method TO15 [4]. Meteorological measurements (wind speed and wind direction) were also collected from the station located at the Winton Montessori School.

Volatile organic compounds were analyzed by gas chromatography/mass spectroscopy in full scan mode [4]. Target VOCs that were typically reported are listed in Table 1. Compounds that are also listed as HAPs are indicated in the table showing the class of health effect associated with the chemical [1]. The analytical detection limit expected for most compounds was 0.1 parts per billion by volume (ppbv). When a target compound was not detected, it was reported as "ND".

Table 1. Target volatile organic compounds.

\begin{tabular}{|c|c|c|}
\hline Dichlorodifluoromethane & $1,1,2,2$-tetrachloroethane ${ }^{C}$ & Freon $113^{*}$ \\
\hline Chlorodifluoromethane & m-dichlorobenzene & Freon $114^{* *}$ \\
\hline Chloromethane $\mathrm{CNC}$ & o-dichlorobenzene & n-butane \\
\hline Vinyl chloride ${ }^{\mathrm{C}}$ & Trichlorofluoromethane & n-pentane \\
\hline Bromomethane $^{\mathrm{C}, \mathrm{NC}}$ & 1,3-butadiene ${ }^{\mathrm{C}}$ & Carbon disulfide $^{\mathrm{NC}}$ \\
\hline Chloroethane & 1,3,5-trimethylbenzene & Hexane $^{N C}$ \\
\hline 1,1-dichloroethene ${ }^{\mathrm{C}, \mathrm{NC}}$ & 1,2,4-trimethylbenzene & n-octane \\
\hline 3-chloropropene & 1,2,4-trichlorobenzene ${ }^{\mathrm{NC}}$ & Chloroform $^{\mathrm{C}}$ \\
\hline Methylene chloride $^{\mathrm{C}}$ & Hexachlorobutadiene ${ }^{C, N C}$ & Bromoform $^{C}$ \\
\hline 1,1-dichloroethane ${ }^{c}$ & Trans-1,2-dichloroethene & Benzene $^{C}$ \\
\hline Cis-1,2-dichloroethene & Bromodichloromethane & Toluene $^{\mathrm{NC}}$ \\
\hline 1,1,1-trichloroethane ${ }^{\mathrm{NC}}$ & Dibromochloromethane & Vinyl acetate ${ }^{C, N C}$ \\
\hline Carbon tetrachloride $^{\mathrm{C}}$ & p-dichlorobenzene ${ }^{C . N C}$ & $m+p$-xylene ${ }^{N C}$ \\
\hline 1,2-dichloroethane ${ }^{\text {C, NC }}$ & Benzyl chloride ${ }^{\mathrm{C}, \mathrm{NC}}$ & o-xylene ${ }^{\mathrm{NC}}$ \\
\hline Trichloroethene $^{\mathrm{C}}$ & Dibromomethane & Styrene $^{\text {NC }}$ \\
\hline 1,2-dichloropropane ${ }^{\mathrm{C}, \mathrm{NC}}$ & Naphthalene ${ }^{\mathrm{NC}}$ & n-heptane \\
\hline Cis-1,3-dichloropropene ${ }^{C}$ & Cyclohexane & n-nonane \\
\hline Trans-1,3-dichloropropene ${ }^{\mathrm{C}}$ & n-propylbenzene & Decane \\
\hline 1,1,2-trichlorethane ${ }^{\mathrm{NC}}$ & a-methylstyrene & Cumene \\
\hline Tetrachloroethene ${ }^{\mathrm{C} . \mathrm{NC}}$ & Dimethylketone-acetone & n-undecane \\
\hline 1,2-dibromoethane ${ }^{\mathrm{C}, \mathrm{NC}}$ & 2-butanone - MEK ${ }^{\mathrm{NC}}$ & n-dodecane \\
\hline Chlorobenzene $^{\mathrm{NC}}$ & $\begin{array}{l}\text { Methyl t-butyl ether - } \\
\text { MTBE C }\end{array}$ & \\
\hline Ethylbenzene ${ }^{\mathrm{NC}}$ & 4-methyl 2-pentanone & \\
\hline
\end{tabular}

${ }^{C}$ HAP with USEPA carcinogenic benchmark [1]

${ }^{\mathrm{NC}}$ HAP with USEPA non-carcinogenic benchmark [1]

A comprehensive quality assurance plan was in place throughout the air monitoring project to ensure the data produced were of acceptable precision, 
accuracy, completeness, representativeness, and comparability. The Quality Assurance Plan covered all aspects as required by the U.S. EPA [5].

\subsection{Receptor modeling to identify landfill and vehicle emission}

The chemical mass balance (CMB) model uses the unique chemical pattern (or fingerprint) of emission for a source as a tracer to quantify the source's contribution to ambient VOC. The CMB general equation is [6]:

where:

$$
Y_{i}=Z_{i, j} \beta_{j}+E_{i}
$$

$Y_{i}=$ concentration of molecule $i$ in ambient air (i.e. the speciated ambient concentration) with units of $\mu \mathrm{g}$ of species i per $\mathrm{m}^{3}$

$Z_{i, j}=$ weight fraction (fingerprint) of species $i$ for source $j$ with units of $\mu g$ of species i per $\mu \mathrm{g}$ of total VOC from source $j$

$\beta_{j}=$ VOC concentrations from source $j$ at the receptor, with units of $\mu \mathrm{g}$ of VOC per $\mathrm{m}^{3}$ from source $\mathrm{j}$

$E_{i}=$ error for species $i$ (measured concentration minus predicted concentration)

Fingerprints are the chemical pattern of species emitted from a source, expressed as the mass fraction of total VOC emission. Fingerprints constitute the independent variable in the model. The landfill and vehicle traffic on surrounding highways have historically been suspected to be contributors to area pollution, and were chosen to be the sources in this model. The VOCs included in the model were common to landfill and/or vehicle emission or found frequently during the monitoring project. The landfill fingerprint was developed from a series of landfill gas analyses performed from 1988-1992 [7]. Each analysis yielded similar results, and therefore was assumed to be an accurate representation of the landfill emission during the study period. Landfill gas compositions were averaged to create a fingerprint. The vehicle emission fingerprint from a previously published paper was used [8]. Table 2 shows the landfill and vehicle fingerprints.

Error in gas chromatography varies with concentration and increases as the concentration approaches the detection limit. This measurement error $(\sigma)$ is used to weight observations in equation 1 so those with greater error have less influence on the solution. For this model, the weighting factor was $1 /(\sigma)^{2}$, where

$$
\sigma=\left((0.1 * \text { concentration })^{2}+(\text { detection limit })^{2}\right)^{1 / 2}
$$

Weighted least squares regression was used to solve equation (1) with the weight defined as $1 /(\sigma)^{2}$. Several model assumptions are important to note. Because the model is a mass balance, it is assumed that the species being modeled do not react or deposit in the atmosphere (i.e. mass is conserved). While this assumption is seldom completely satisfied, the most important aspect is that the chemical emission pattern from each source does not significantly change between the source and receptor points. Species used as fitting 
compounds are chosen to have similar low reactivities. When travel times between the sources and receptor are on the order of a few hours, previous studies have shown that reactivity does not significantly alter the source fingerprints [6]. Other requirements are the compositions of emissions at the source are relatively constant, all major sources are included in the model, and that source compositions are linearly independent.

Table 2. Source fingerprints (weight fraction of total VOC)

\begin{tabular}{|l|c|c|}
\hline VOC & Landfill & Vehicle \\
\hline Acetone & 0.0087 & 0.0035 \\
\hline Benzene & 0.0094 & 0.0338 \\
\hline n-butane & 0.0000 & 0.0540 \\
\hline Methyl ethyl ketone & 0.0000 & 0.0000 \\
\hline Carbon disulfide & 0.0000 & 0.0000 \\
\hline Chlorodifluoromethane & 0.0000 & 0.0000 \\
\hline Chloromethane & 0.0000 & 0.0000 \\
\hline Decane & 0.0000 & 0.0016 \\
\hline Dichlorodifluoromethane & 0.0000 & 0.0000 \\
\hline Ethylbenzene & 0.0988 & 0.0114 \\
\hline Hexane & 0.0000 & 0.0124 \\
\hline Methylene chloride & 0.1145 & 0.0000 \\
\hline n-pentane & 0.0000 & 0.0288 \\
\hline Styrene & 0.0100 & 0.0000 \\
\hline Tetrachloroethene & 0.0832 & 0.0000 \\
\hline Toluene & 0.2954 & 0.0791 \\
\hline $1,1,1$-trichloroethane & 0.0084 & 0.0000 \\
\hline Trichlorofluoromethane & 0.0000 & 0.0000 \\
\hline $1,2,4-$ trimethylbenzene & 0.0000 & 0.0143 \\
\hline Xylene & 0.3305 & 0.0531 \\
\hline
\end{tabular}

\subsection{Establishment of the relationship between pollutant emissions and concentration}

To show evidence of an emission, a relationship must be established between the period of time a monitor is downwind from the source and the monitored concentration. For the receptor model determination of landfill gas concentrations, the distribution of wind speed and directions were compared on the days of the highest contributions and lowest contributions. In this way, the wind directions associated with the highest landfill concentrations can be directly evaluated.

\section{Results}

Table 3 is a summary of selected target VOC concentrations. All compounds that were always detected, or frequently detected are included in this table. The table shows the median concentrations from the four Winton Hills/Place 
monitors and the comparison Dater monitor. Median concentrations were selected for these tables as the best single measure of the typical concentrations at these locations.

For most compounds frequently detected, the concentrations at the four Winton Hills/Place monitors are very similar. For example, the median concentrations of acetone in Winton Hills/Place ranged from 5.6 to $6.6 \mathrm{ppb}$, and the range for benzene was 0.40 to $0.60 \mathrm{ppb}$. No one Winton Hills/Place site was clearly higher than the others. The firehouse had a tendency to have slightly higher median concentrations for many of the compounds (acetone, benzene, n-butane, ethylbenzene, hexane, n-octane, n-pentane, toluene, 1,2,4trimethylbenzene, o-xylene and $\mathrm{m}, \mathrm{p}$-xylene); however, in all cases the differences within the community are relatively small.

In contrast, there are differences between the Winton Hills/Place and comparison (Dater) monitors. Of the frequently found VOCs, benzene, n-butane, ethylbenzene, hexane, 1,2,4-trimethylbenzene, o-xylene and $\mathrm{m}$, p-xylene are significantly higher in the Winton Hills/Place communities compared to the concentrations at the comparison Dater monitor. In addition to these compounds, toluene, chloromethane, and trichlorofluoromethane are consistently higher in the Winton Hills/Place communities although the differences are not significant. This pattern is consistent with the presence of sources of hazardous air pollutant emissions in the Winton Hills/Place communities

Table 3. Frequently found target VOCs, median concentrations, ppb.

\begin{tabular}{|l|c|c|c|c|c|}
\hline \multirow{2}{*}{ Compound } & \multicolumn{3}{|c|}{ Winton Hills/Place sampling locations } & Comparison \\
\cline { 2 - 6 } & Montessori & Firehouse & Jacobs & Metro & Dater \\
\hline Acetone & 5.6 & 6.6 & 6.25 & 5.8 & NS \\
\hline Benzene & 0.4 & 0.6 & 0.43 & 0.46 & 0.34 \\
\hline n-butane & 1.8 & 4.8 & 2.15 & 2.1 & 1.4 \\
\hline Carbon disulfide & 0.9 & 0 & 0 & 0.7 & 0.9 \\
\hline Chlorodifluoromethane & 0.29 & 0.23 & 0.23 & 0.3 & 0.24 \\
\hline Chloromethane & 0.64 & 0.6 & 0.62 & 0.72 & 0.55 \\
\hline Dichlorodifluoromethane & 0.6 & 0.6 & 0.6 & 0.68 & 0.6 \\
\hline Ethylbenzene & 0.19 & 0.2 & 0.18 & 0.2 & 0 \\
\hline Hexane & 0.7 & 1.5 & 0.83 & 0.85 & 0 \\
\hline Methylene chloride & 0 & 0.1 & 0 & 0 & 0 \\
\hline Naphthalene & 0 & 0.04 & 0.05 & 0 & 0 \\
\hline N-octane & 0.05 & 0.1 & 0 & 0 & 0 \\
\hline N-pentane & 0.14 & 0.52 & 0.29 & 0 & 0.57 \\
\hline Toluene & 1.15 & 1.6 & 1.25 & 1.4 & 0.68 \\
\hline Trichlorofluoromethane & 0.3 & 0.3 & 0.3 & 0.31 & 0.26 \\
\hline $1,2,4$-trimethylbenzene & 0.27 & 0.4 & 0.21 & 0.29 & 0 \\
\hline O-xylene & 0.2 & 0.3 & 0.21 & 0.22 & 0 \\
\hline m, p-xylene & 0.59 & 0.8 & 0.66 & 0.62 & 0.3 \\
\hline
\end{tabular}

The landfill and surrounding highways have been suspected as major sources of air pollution in the Winton Hills/ Winton Place communities. Because of this, 
the CMB model was used to determine the contribution of landfill and vehicle emissions to monitored concentrations. Table 4 shows the average total VOC emission for each source by site in $\mu \mathrm{g} / \mathrm{m}^{3}$.

Table 4: Receptor model results by monitoring site, $\mu \mathrm{g} / \mathrm{m}^{3}$.

\begin{tabular}{|l|c|c|c|c|}
\hline \multirow{2}{*}{ Site } & \multicolumn{2}{|c|}{ Landfill } & \multicolumn{2}{c|}{ Vehicle } \\
\cline { 2 - 5 } & Average & St. Dev. & Average & St. Dev \\
\hline Montessori & 2.898 & 3.895 & 56.759 & 31.167 \\
\hline Metro & 5.125 & 6.197 & 56.112 & 19.027 \\
\hline Jacobs & 2.629 & 2.770 & 58.553 & 27.250 \\
\hline Firehouse & 5.484 & 7.594 & 78.792 & 47.120 \\
\hline Dater Jr. High & 0.640 & 1.510 & 46.920 & 30.740 \\
\hline
\end{tabular}

For all sites, the contribution of vehicle emissions is much greater than that of the landfill. However, the model also shows that the landfill is also contributing to area VOC concentrations. The contribution of the landfill is significantly higher $(\mathrm{p}<0.001)$ in the study area than at the comparison site. The model was not able to estimate landfill emissions in 29 out of 118 total samples at the Winton Hills/Place study sites. In comparison, the model was not able to estimate landfill emissions in 20 of 26 sampling days at Dater Jr. High. Table 5 shows the average contributions of each VOC allocated by the model at the Jacobs site.

Table 5: Average concentrations of VOCs at Jacobs monitoring site, $\mu \mathrm{g} / \mathrm{m}^{3}$.

\begin{tabular}{|l|c|c|c|c|}
\hline VOC & Measured & Landfill & Vehicle & Residual \\
\hline Acetone & 13.795 & 0.023 & 0.205 & 13.568 \\
\hline Benzene & 1.583 & 0.025 & 1.979 & -0.421 \\
\hline n-butane & 15.405 & 0.000 & 3.162 & 12.243 \\
\hline Methyl ethyl ketone & 1.333 & 0.000 & 0.000 & 1.333 \\
\hline Carbon disulfide & 1.447 & 0.000 & 0.000 & 1.447 \\
\hline Chlorodifluoromethane & 0.991 & 0.000 & 0.000 & 0.991 \\
\hline Chloromethane & 1.839 & 0.000 & 0.000 & 1.839 \\
\hline Decane & 2.156 & 0.000 & 0.094 & 2.062 \\
\hline Dichlorodifluoromethane & 2.459 & 0.000 & 0.000 & 2.459 \\
\hline Ethylbenzene & 0.792 & 0.260 & 0.667 & -0.136 \\
\hline Hexane & 3.463 & 0.000 & 0.726 & 2.737 \\
\hline Methylene chloride & 0.244 & 0.301 & 0.000 & -0.052 \\
\hline n-pentane & 0.960 & 0.000 & 1.686 & -0.762 \\
\hline Styrene & 0.217 & 0.026 & 0.000 & 0.190 \\
\hline Tetrachloroethene & 0.254 & 0.219 & 0.000 & 0.035 \\
\hline Toluene & 4.794 & 0.778 & 4.632 & -0.615 \\
\hline $1,1,1$-trichloroethane & 0.255 & 0.022 & 0.000 & 0.233 \\
\hline Trichlorofluoromethane & 1.529 & 0.000 & 0.000 & 1.529 \\
\hline $1,2,4$-trimethylbenzene & 1.195 & 0.000 & 0.837 & 0.357 \\
\hline Xylene & 5.284 & 0.870 & 3.109 & 1.304 \\
\hline
\end{tabular}


In the receptor model, methylene Chloride, styrene, tetrachloroethylene, and 1,1,1-trichloroethane are VOCs that are only emitted by the landfill. The small residual for methylene chloride and tetrachloroethylene indicates that the landfill is the dominant source of these VOCs in the area. In contrast, residual styrene and 1,1,1-trichloroethane indicates other sources in the area.

Benzene, ethylbenzene, toluene and xylene are modeled as landfill and vehicle emissions. The model accounted for all of the benzene and ethylbenzene within the study area. This suggests that there are no other sources of these VOCs at this site. In contrast, residual xylene is found at all monitoring sites, showing evidence of other sources. The picture of toluene is mixed. The model does not account for all of the toluene at the Firehouse and Metro sites. However, no residual toluene was found at the Jacobs and Montessori sites.

A number of VOCs were also included in the model as vehicle emissions. Residual n-butane, decane, hexane, and 1,2,4-trimethylbenzene were found, indicating other sources of these VOC's. At the Montessori, Metro and Jacobs sites, n-pentane was attributed to vehicles only, while at the Firehouse residual npentane was found. This indicates a possible localized source, whose emissions may not have reached the other sites (i.e. a gas station).

Other VOCs included in the model were not part of the landfill or vehicle fingerprints. These were included in the model because they were found frequently during monitoring and are most likely attributable to point sources.

To evaluate the receptor model concentrations, plots were developed comparing the days of highest and lowest predicted concentration. These plots identify the dominant wind direction associated with the sources. Figure 1 shows this for the landfill emissions at the Jacobs site. The plots show the predominant wind directions associated with high landfill concentrations are north, northeast and east. These directions are consistent with the location of the landfill. It is also interesting to note that the majority of the wind speeds associated with high concentrations are low. The plots of the vehicle contributions are not as clear. A specific pattern (wind direction) for high concentrations is not identified in these plots. This finding is consistent with the fact that the monitors are almost completely surrounded by expressways. 

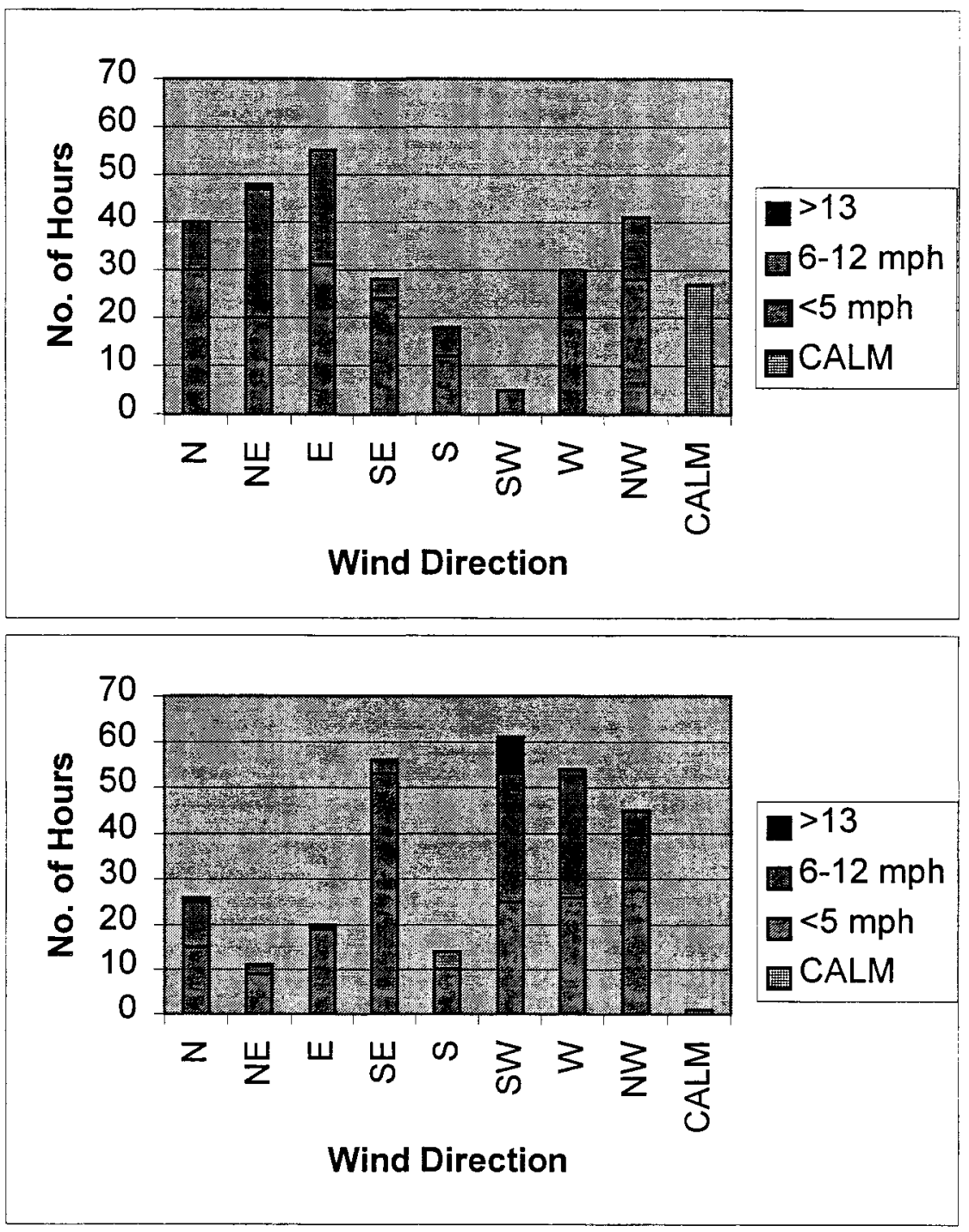

Figure 1: Wind conditions at Jacobs for 12 highest $\left(>2 \mu \mathrm{g} / \mathrm{m}^{3}\right)$ (top) and lowest $\left(<2 \mu \mathrm{g} / \mathrm{m}^{3}\right)$ (bottom) days of estimated landfill concentration. 


\section{Conclusions}

The location of the Winton Hills and Winton Place communities potentially exposes the residents to pollutant emissions from many sources. Landfills within the community were believed to be sources of hazardous air pollutants. Comparison of concentrations between monitoring sites shows that for most compounds frequently identified, the concentrations at the four Winton Hills/Place monitors are fairly similar. There were a few differences in concentration between the Winton Hills/ Place monitors and the comparison Dater monitor with benzene, n-butane, ethylbenzene, hexane, 1,2,4trimethylbenzene, o-xylene, and m,p-xylene concentrations significantly higher in the Winton Hills/Place communities.

The CMB model showed that landfill and vehicle emissions are the major sources of benzene in the Winton Hills/Place area. Wind speed and direction frequency plots for BTEX indicate a source in the northeast and east, consistent with the position of the landfill. The model also showed that methylene chloride was related to landfill emissions. Toluene and xylene were found being emitted from vehicles, the landfill, and additional point sources in the area. The landfill was also found to be the major contributor of perchloroethylene in the community. Both the landfill and vehicles were found to be sources of acetone. Source apportionment also indicated the presence of additional point sources.

\section{References}

[1] Caldwell, J.C., Woodruff, T.J, Morello_Frosch, R., \& Axelrad, D.A. Application of health information to hazardous air pollutants modeled in EPA's Cumulative Exposure Project. Toxicology and Industrial Health, 14(3), pp. 429-454, 1988.

[2] Scheff, P.A. \& Casten, C. Data Summary Report: Air Monitoring Study in Winton Hills/Place. Prepared for the Hamilton County Department of Environmental Services, Air Quality Division, July, 2000.

[3] U.S. Environmental Protection Agency, Toxic Release Inventory, 1994.

[4] U.S. Environmental Protection Agency, Method TO15: Determination of VOCs in Air Collected in Specially-Prepared Canisters and Analyzed by Gas Chromatography Mass Spectrometry. In: Compendium of Methods for the Determination of Toxic Organic Compounds in Ambient Air, Office of Research and Development, Center for Environmental Research Information, Cincinnati, OH, 1999.

[5] EPA Quality Assurance Handbook for Air Pollution Measurement Systems. (EPA 600/9-76-005; 600/4-77-027A; 600/4-82-060).

[6] Scheff, P.A. \& Wadden, R.A. Receptor modeling of VOCs: I. Emission inventory and validation. Environ. Sci. and Technol., 27, pp. 617-625, 1993.

[7] Personal communication, Mary Knochelmann, Manager of Safety and Compliance, Waste Management Inc., May 1, 1995

[8] Scheff, P., Wadden, R., Kenski, D., Chung, J., \& Wolff, G. Receptor Model Evaluation of the Southeast Michigan Ozone Study Ambient NMOC Measurement. JAWMA, 46, pp. 1048-1057, 1996. 